\title{
DEVELOPMENT OF DESIGN PROCEDURES FOR THE FLEXURAL STRENGTH AND DUCTILITY OF REINFORCED CONCRETE BRIDGE COLUMNS
}

\author{
F. A. Zahn', R. Park ${ }^{2}$, M. J. N. Priestley ${ }^{3}$ and H. E. Chapman ${ }^{4}$
}

\author{
ABSTRACT \\ The assumptions and methods of analysis used to define the \\ flexural strength and the available limit curvature of \\ reinforced concrete columns sections are discussed. The results \\ of cyclic moment-curvature analyses of a large range of \\ reinforced concrete column sections, using cyclic stress-strain \\ relationships for the steel and for the concrete, are outlined \\ and the important variables and their influence on the \\ available strength and curvature ductility are identified. \\ Examples of design charts derived from these analytical results \\ are discussed and a flow chart outlining the whole seismic \\ resistance design procedure for bridge piers is introduced. \\ The quantity of confining steel determined using the design \\ charts is compared with the corresponding quantity required \\ by the current New Zealand concrete design code equations. \\ Finally a possible future development is discussed that would \\ lead to an improvement of the code design method used to \\ provide sufficient ductility in the plastic hinges of \\ reinforced concrete columns.
}

\section{INTRODUCTION}

During recent years much research into the behaviour of reinforced concrete columns subjected to seismic loading has been undertaken at the University of Canterbury, mostly sponsored by the Road Research Unit of the National Roads Board. The need to be able to predict the seismic resistance of the columns of bridge substructures has been recognised for many years, particularly since the San Fernando earthquake in California in 1971 which caused significant damage to bridges. When seismic induced energy in a bridge is designed to be dissipated by plastic hinging, the hinges are commonly located in the piers, due to the structural form of a bridge. Whilst a "column hinge mechanism" is usually considered undesirable in tall building frames, it is often unavoidable in bridge substructures [1]

For design office use, design aids are necessary to enable designers to readily evaluate the available flexural strength and ductility in proposed members in order to match the available and required values. Because this is a complex subject, the design aid used must simplify the calculation process whilst taking into account all important variables. The

1. Assistant Engineer, Ministry of Works and Development, Wellirigton, New Zealand.

2. Professor of Civil Engineering, University of Canterbury, New Zealand.

3. Reader in Civil Engineering, University of Canterbury, New zealand.

4. Design Engineer, Ministry of Works and Development, Wellington, New Zealand. first such design aid for flexural ductility was produced by the Ministry of Works and Development (MWD) in 1975 [2]. Sufficient research work has since been completed to allow a full revision of this document to be undertaken by MWD, based on the results of recent University of Canterbury research projects. That research has shown that the use of closely spaced hoops or spiral bars not only increases the available flexural ductility of column sections but also the flexural strength. The revised design aids therefore provide information for evaluation of both the flexural ductility and the flexural strength.

This paper describes the background, research results, and the procedure included in the revised design aid publication being developed by the MWD for the design of reinforced concrete bridge columns.

\section{BACKGROUND}

In order to achieve a particular curvature ductility factor, a greater quantity of confining steel must be placed in the potential plastic hinge regions of columns subjected to large axial compressive loads than in lightly loaded columns. This is because the internal forces providing the moment of resistance depend more heavily on the contribution from the confined concrete when the neutral axis depth is large. This has been recognised in the confining steel equations in section 6 of NZS 3101 [1], where the quantity of confining steel varies linearly with the ratio $\mathrm{P} / \phi \mathrm{f}^{\prime} \mathrm{A}$. Those NZS 3101 equations are for circaliar hoops or spirals: 


$$
\begin{aligned}
& \rho_{s}=0.45\left(\frac{g}{A_{c}}-1\right) \frac{f_{c}^{\prime}}{f_{y h}}\left(0.5+1.25 \frac{P_{e}}{\phi f_{C}^{\prime A}}\right) \\
& \rho_{s}=0.12 \frac{f_{c}^{\prime}}{f_{y h}}\left(0.5+1.25 \frac{P_{e}}{\phi f_{c}^{\prime A}}\right)
\end{aligned}
$$

whichever is greater, and for rectangular hoops and/or cross ties:

$$
\begin{aligned}
& A_{s h}=0.3 s_{h} h^{\prime \prime}\left(\frac{A_{g}}{A_{c}}-1\right) \frac{f_{c}^{\prime}}{f_{y h}}\left(0.5+1.25 \frac{P_{e}}{\phi f_{c}^{\prime} A_{g}}\right) \\
& A_{s h}=0.12 s_{h} h^{\prime \prime} \frac{f_{C}^{\prime}}{f_{y h}}\left(0.5+1.25 \frac{P_{e}}{\phi f_{C_{g}^{\prime}}^{\prime}}\right)
\end{aligned}
$$

whichever is greater. The strength reduction factor $\phi$ is equal to 0.9 .

Eqs. 1 to 4 are intended to provide adequate ductility for the range of structures which are permitted by NZS 3101 to develop plastic hinges in columns as part of the mechanism of inelastic deformation during a severe earthquake. These NZS 3101 equations for confining steel result in a particular available curvature ductility factor, typically shown by tests to be at least 20 [3]. It is evident that the code equations will provide an excess of confining steel in cases of low ductility demand, and in cases of large ductility demand may result in an insufficient quantity of confining steel. Trie MWD publication CDP 810/A "Ductility of Bridges with Reinforced Concrete Piers" [2] goes a step further in giving design charts which specifically relate the quantities of transverse steel to the required curvature ductility factor.

The MWD charts, as well as the NZS 3101 equations, were derived from theoretical monotonic moment-curvature analyses of a range of reinforced concrete column cross sections and for different axial load ratios. However laboratory tests and theoretical moment-curvature analyses, conducted at the University of Canterbury in recent years (see for example Refs. 3, 4 and 5), have shown that reinforced concrete columns subjected to high axial compression loads and cyclic lateral loading may undergo a significant deterioration of flexural strength with continued cycling between large positive and negative curvatures. That theoretical work conducted at the University of Canterbury has greatly improved the understanding of the interaction between the transverse steel and the confined core concrete. In particular, the development by Mander et al [4] of cyclic stress-strain models for confined concrete and for reinforcing steel has provided an accurate basis on which to model analytically the cyclic momentcurvature behaviour of reinforced concrete columns.

In addition, Mander et al [4] have proposed an "energy balance" method to predict the stage of hoop or spiral bar fracture. The energy balance method reflects the principle that the lateral expansion of the core concrete at large compression strains is passively resisted by the confining steel, which has to follow that expansion, thus absorbing strain energy. The increase in strain energy capacity of the compressed concrete due to confinement is assumed to be provided by the strain energy capacity of the confining reinforcement as it yields in tension. Hoop or spiral fracture occurs when the strain energy stored in the compressed concrete as a result of the confinement is equal to the strain energy absorption capacity of the confining steel. The strain energy stored in the concrete as a result of confinement is equal to the difference in area between the stress-strain curves for confined and unconfined concrete (the shaded area of Fig. 1) multiplied by the volume of confined concrete. The strain energy capacity of the confining steel is equal to the area under the stress-strain curve of the confining steel (up to the fracture strain) multiplied by the volume of that steel confining the concrete.

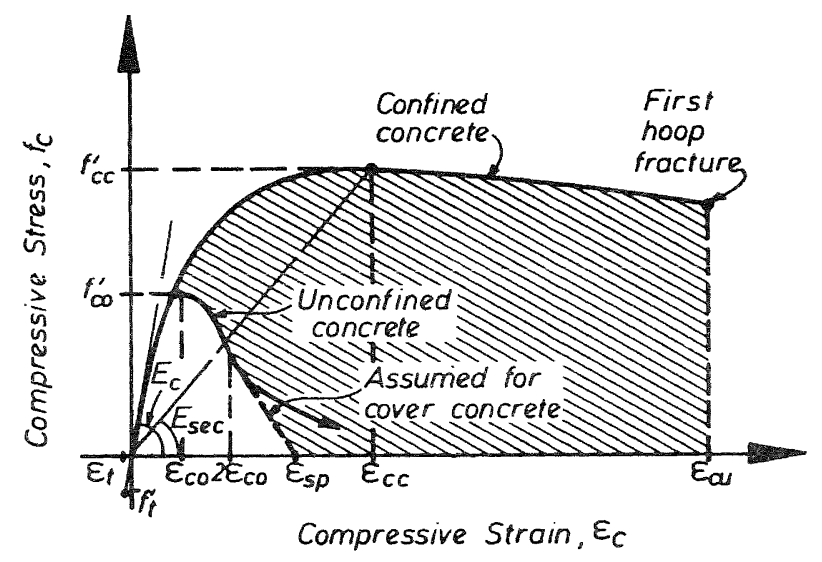

Fig. 1 Stress-Strain Curves for Confined and Unconfined Concrete [4].

If the strain energy accumulated in a hoop or spiral bar over a number of curvature cycles in the inelastic range has reached the energy absorption capacity of the transverse bar, causing it to fracture, the section may be considered to be at an ultimate limit state since then the concrete is no longer effectively confined.

It is evident that the possible reduction in the flexural strength of columns during cyclic loading, and the possible fracture of transverse reinforcement due to an accumulation of strain energy as a result of cyclic loading, may have a major bearing on the available curvature ductility of a column. Therefore it was considered necessary to derive the design aids from the results of cyclic moment-curvature analyses rather than monotonic analyses. A computer program developed by Mander et al [4], which takes these effects into account, was modified to include a set of criteria that determine whether the section is at an ultimate limit state. 


\section{DEFINITION OF AVAILABLE ULTIMATE}

A sequence of four identical cycles of imposed bending moment, to peak curvatures of equal magnitude in both the positive and the negative directions, was adopted as the standard by which the available curvature ductility of reinforced concrete column sections is measured. The section is considered to have reached its available ultimate curvature when one or both of the following conditions is reached:

(a) The moment resisted at either the positive or the negative peak of the last cycle has reduced to $0.8 \mathrm{M}_{1}$, where $M_{i}$ is the ideal flexural strength of the section.

(b) The strain energy accumulated in the confining steel at the end of the four cycles is equal to its strain energy absorption capacity.

The peak curvature for which one or both of these conditions applies is then defined as the available ultimate curvature, $\phi_{u}$.

The performance criterion of four loading cycles to a particular ductility level without the flexural capacity reducing by more than $20 \%$ is similar to that proposed in the commentary of N2S 4203 for buildings [6].

The definition of available ultimate curvature of reinforced concrete column sections adopted here is illustrated in Figs. 2 and 3 . For the column section in Fig. 2 the available ultimate curvature $\phi_{u}$ is governed by moment deterioration to $0.8 \mathrm{M}$ it the end of four cycles to $\pm \phi_{\mathrm{u}}$ without fracture of the hoop steel occurring. For the column section in Fig. 3 , the available ultimate curvature is governed by hoop fracture at the end of four cycles to $\pm \phi_{u}$, without the moment reducing to $0.8 \mathrm{M}_{i}$.

It is not known before the analysis commences whether four cycles to a particular curvature peak, фpeak' will actually produce an ultimate peak limit state as defined above. However the available ultimate curvature can only be determined by an iterative process. The section is analysed for the standard sequence of four cycles to a first estimate of $\phi$ peak. If the ultimate limit conditions are potak satisfied, the entire cyclic analysis is repeated for improved estimates of $\phi$ peak until the conditions are satisfied, indiegakng that the final value of $\phi_{\text {peak }}$ is equal to the available ultimate curvature $\phi_{\mathrm{u}}$.

It is worth noting that in these moment-curvature analyses no explicit limitation was imposed on the maximum concrete compression strain. Some previous definitions for available ultimate curvature have included a limiting concrete compressive strain. However it is now recommended that the two criteria described above give an adequate measure of the available curvature ductility of the section.
Numerous column tests have shown that compressive strains as high as 0.09 can be tolerated by well confined concrete (see, for example, Refs. 3, 4 and 5). Also, in these analyses no explicit limitation was imposed on the longitudinal steel strains. Again it was found in tne tests that at the levels of ultimate curvature required in design, fracture of the longitudinal steel in tension did not occur and that premature buckling of longitudinal steel in compression can be suppressed by ensuring that the spacing of transverse reinforcement provided in plastic hinge regions is appropriately close.

\section{DEFINITION OF IDEAL FLEXURAL STRENGTH}

In Figs. 2 and $3, M_{i}$ is the ideal flexural strength and $M^{1}$ is the maximum resisted moment duaxing the four cycles. Note that $M$ could occur anywhere along the hysteresis loops, for example at one of the curvature peaks.

In this study the ideal flexural strength, M. is defined as the maximum moment reached in the initial (positive) half cycle before the section curvature exceeds 5 times the yield curvature. That means that any strength enhancement of the concrete due to confinement is taken into account in the calculation of $M$. but strain hardening of the flexural steel has not usually commenced at that stage.

The effect of both confinement of concrete and strain hardening of steel is included in calculating the maximum moment, $M$, which is used to define the overstrength moment. Therefore the value for $M$ is determined taking into account the overstrength material properties for the concrete and for the flexural steel. It is worth noting that for both $M_{i}$ and $M_{\max }$ the observed in fast strain rate tests (see, for example, Ref. 4) should be taken into account.

\section{DESIGN CHARTS TO DETERMINE THE CURVATURE DUCTILITY FACTOR}

Fig. 4 shows an example of the curvature ductility design charts derived for circular reinforced concrete column sections. The chart relates the available curvature ductility factor, $\phi_{1} / \phi_{\mathrm{y}}$, at the critical section of the plastlc $y_{\text {hinge to }}$ the magnitude of the lateral confining stress, $f$, acting on the core concrete. As expected the axial load ratio $\mathrm{P} / \mathrm{f}_{\mathrm{C}}^{\mathrm{A}} \mathrm{g}$ is the major variable. The charts are in dimensionless form to facilitate their use for different section dimensions and material strengths. Note that the stress $f^{\prime}$ used to normalise the lateral confining stress, $f$, is the assumed unconfined in situ strength of the concrete and is taken as $0.85 f^{\prime}$. The lateral confining stress, $f$, can be related to the diameter of the concrete core of the column and to the diameter, spacing and yield strength of the spiral or circular hoops. The definition for yield curvature, $\phi_{y}$, used in the charts is given in the Notation section of this paper. 


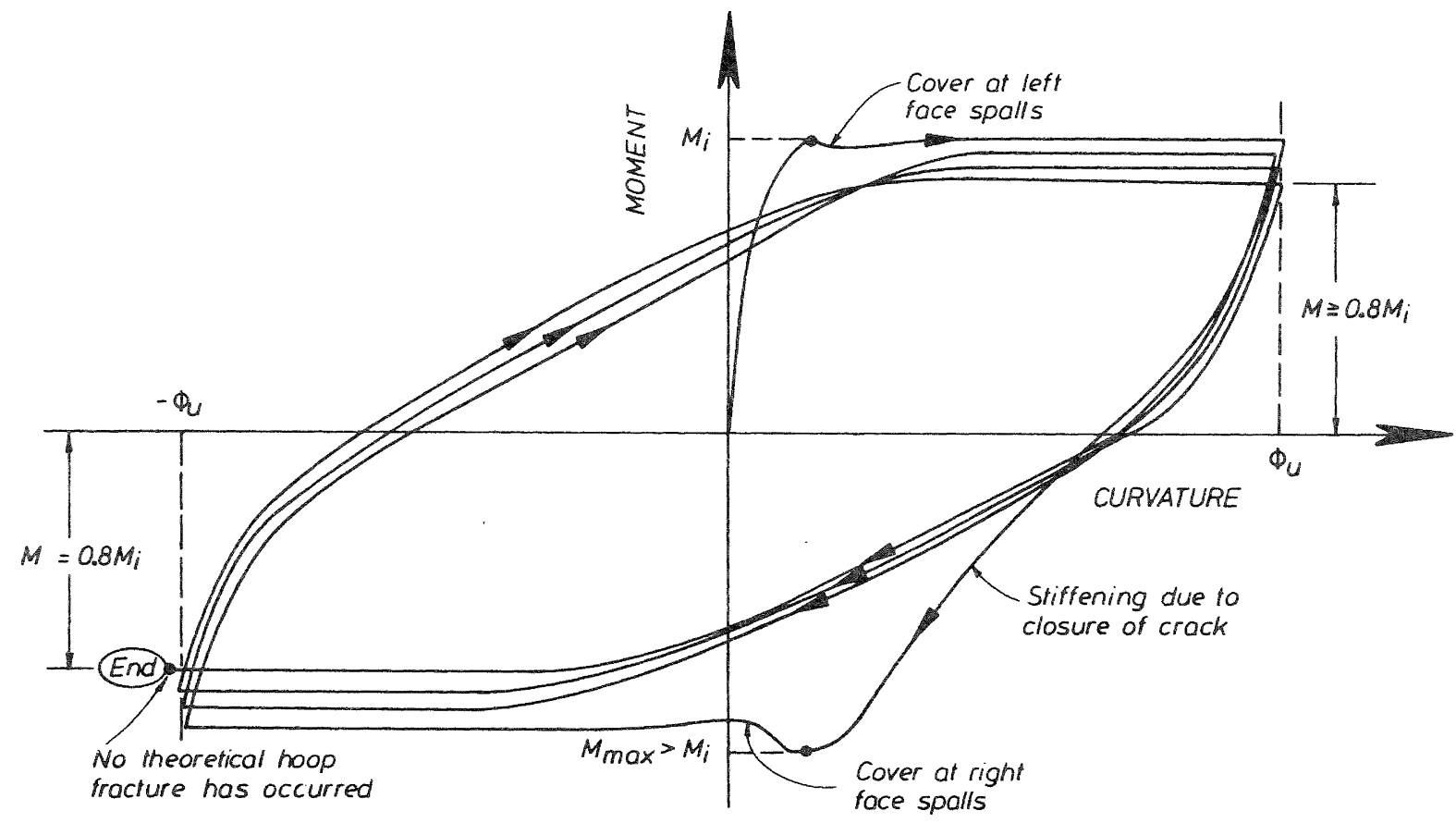

Fig.2 Theoretical Moment-Curvature Relation for a Reinforced Concrete Column Section Illustrating the Case Where Moment Deterioration Governs the Available Ultimate Curvature.

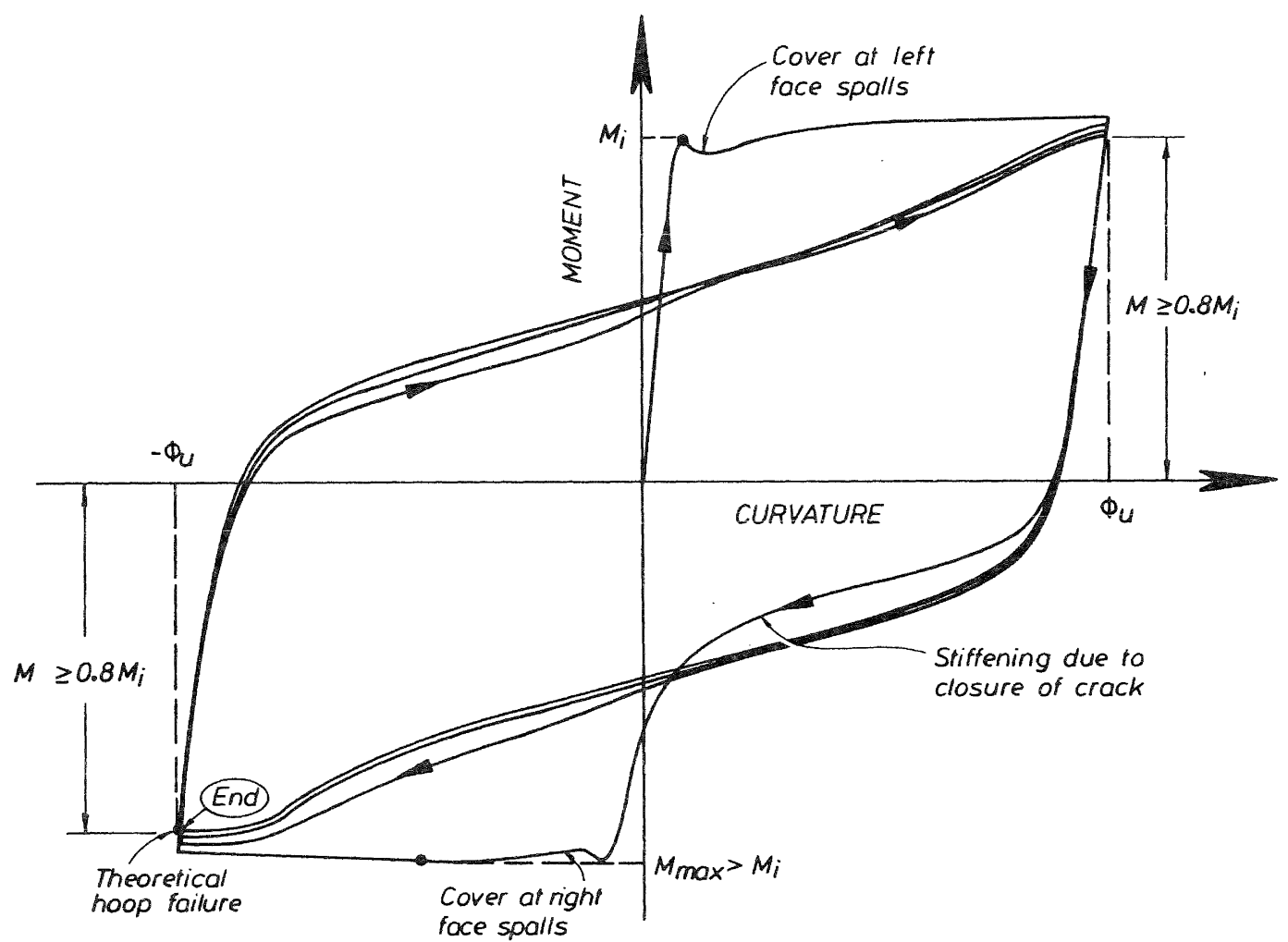

Fig. 3 Theoretical Moment-Curvature Relation for a Reinforced Concrete Column Section Illustrating the Case Where Hoop Fracture Governs the Available Ultimate Curvature. 


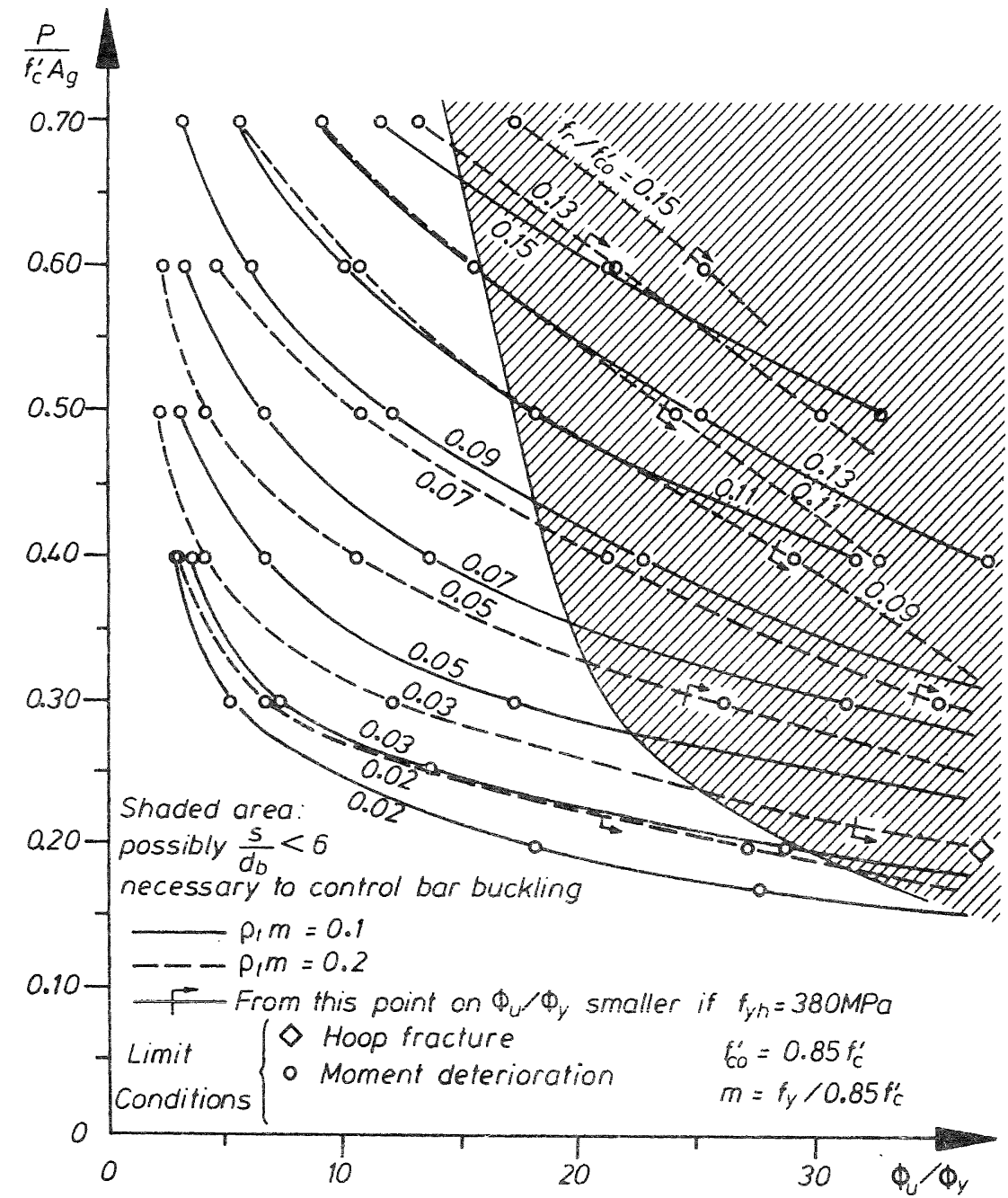

Fig. A Design Chart for Curvature Ductility Factor for Circular Reinforced Concrete Column Sections [5].

The chart shown in Fig. 4 is for a circular section with $\mathrm{f}^{\prime}=30 \mathrm{MPa}, \mathrm{f}_{\mathrm{y}}=$ $275 \mathrm{MPa}, f=275 \mathrm{MPa}, \mathrm{C}^{\mathrm{a}} \mathrm{a}$ mechanical reinforcing ratios of $\rho_{t} m=0.1$ and 0.2 , where $\rho \mathrm{m}=\rho \mathrm{f} / 0.85 \mathrm{f}^{\prime}$. The thickness of the unconfined cover concrete of the section is 68 of the overall section diameter.

From the example of Fig. 4 the following general conclusions can be reached:

(a) The available curvature ductility factor, $\phi / \phi$, rapidly decreases with increasing axial compression load ratio, $P / f_{C}^{\prime} g^{\cdot}$

(b) At very low axial load ratios (<0.15) extremely large curvature ductilities are theoretically available with only very small quantities of confining steel. It is evident, however, that there are other factors that determine the quantity of transverse steel in such cases, for example shear requirements.

(c) The factor that most often governs the ultimate curvature

of the section is the cyclic flexural strength deterioration, as indicated by the "O" symbols in Fig. 4. (d) The available curvature ductility factor for a given confining stress ratio, $f / f$, may be less when Grade 380 steel is used for confinement, as indicated by the "P" symbols in Fig. 4.

(e) The available curvature ductility factor for a given confining stress ratio is greater for greater mechanical reinforcing ratios $\rho_{t} \mathrm{~m}$.

(f) The available curvature ductility factor is further limited by the Iine separating the shaded area from the unshaded area in Fig. 4 for most practical design situations. This is because curvature ductilities that lie within the shaded area require longitudinal steel compression strains likely to cause excessive bar buckling if the hoops are spaced at 6 longitudinal bar diameters as required by the concrete design code [I]. Hoop spacings considerably smaller than $6 \mathrm{~d}_{\mathrm{b}}$ have to be used in order to achieve those curvature ductilities.

The revised design aid publication CDP 810/B [7] will contain charts similar to that shown in Fig. 4. There will be separate charts for different section types (circular and rectangular, including square): different mechanical reinforcing ratios, $\rho_{t} m$; and different relative cover concrete 
thicknesses, C/D. The lateral confining stress, $f$, will be related to the concrete core section dimensions, and the arrangement, diameter and yield strength of the transverse reinforcement, using a set of charts and equations. It is worth noting that the charts are applicable to sections with either New Zealand manufactured Grade 275 or Grade 380 longitudinal bars, provided that $\rho_{t} \mathrm{~m}$ is not greater than 0.3 . Also, the influence of the concrete cylinder strength, f', may be neglected provided that $25 \leqq f_{C}^{F^{\prime}} \leqq 35 \mathrm{MPa}$.

\section{DESIGN CHARTS TO DETERMINE THE FLEXURAL STRENGTH}

Fig. 5 shows an example of the charts derived to determine the ideal flexural strength, $M_{\text {. }}$, of reinforced concrete sections, taking into account the effect of confinement of the concrete and the axial load level. The same dimensionless variables for confining stress, $f_{r} / f^{\prime}$, and axial load level, P/f'A are used as ${ }^{\mathrm{C}}$ In Fig. 4. The charts give the ratio $M_{j} / M_{C o d e}$ where $M_{c o d}$ is the flexural strength of the section code determined using the conventional approach of the concrete design code [1], taking the strength reduction factor $\phi$ as unity. It is evident that for axial compression loads of less than $0.3 f^{\prime} A$ the enhancement of the flexural strength due to confinement is small for the magnitude of confining stress typically used for columns with low axial loads. For the calculation of the maximum moment, $M$, an additional factor has to be applied to $M_{i}$ to allow for the strength enhancement due to strain hardening of the flexural steel. That factor is more or less independent of the axial load ratio.
The revised design aid publication CDP 810/B [7] will contain a set of charts similar to that shown in Fig. 5, for different section types and relative cover concrete thicknesses, c/D.

\section{PROCEDURE FOR DESIGNING REINFORCED CONCRETE COLUMN SECTIONS FOR FLEXURAL STRENGTH AND DUCTIIITY}

The design charts discussed in the previous two sections are part of a comprehensive design procedure that is outlined in the flow chart shown in Fig. 6 . The flow chart provides the basis for the whole design procedure and the user is referred to the appropriate section of the publication or to another reference at each step. Thus the different sections of the publication are widely independent of each other and can be used individually, for example to evaluate the flexural strength and/or ductility of an existing column. Other sections in the publication cover the calculation of the flexural stiffness at yield, the relationship between the curvature ductility factor and structure displacement ductility factor, the relationship between confining stress and the quantity/arrangement of transverse steel, etc.

A new concept is the addition of a serviceability limit state, intended to limit the damage in the plastic hinge zones of a bridge column in the statistically more frequent event of a moderate intensity earthquake. The requirement is that the column should have sufficient strength so that the response displacements during a moderate earthquake correspond to curvature

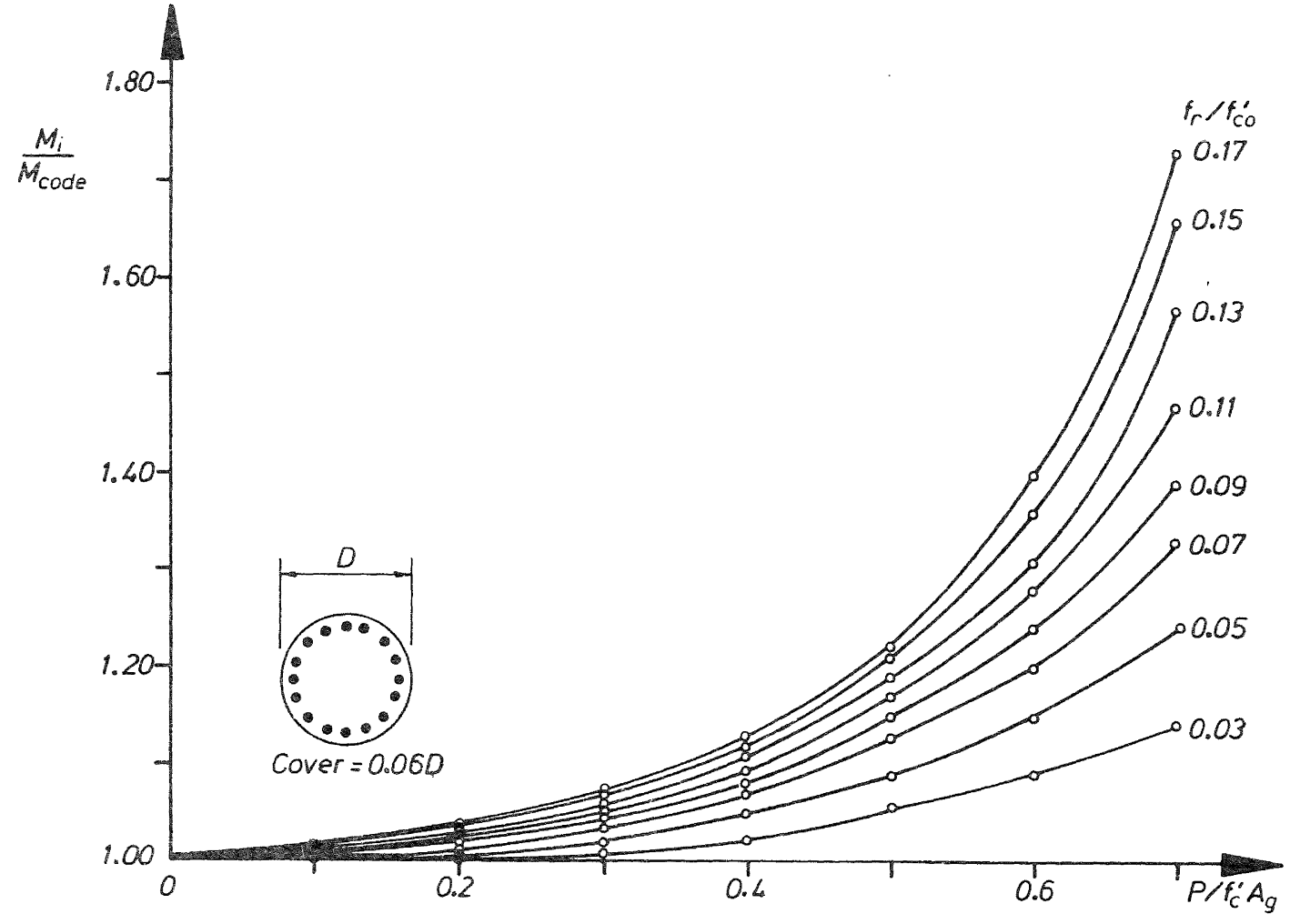

Fig. 5 Design Chart for Flexural Strength Enhancement Factor for Circular Reinforced Concrete Column Sections [5]. 
I. DETERMINE LATERAL DESIGN LOAD AND DESIGN PLASTIC HINGING MEMBER FOR FLEXURAL STRENGTH

Known variables at starting point

$\mathrm{P}_{\mathrm{e}} / \mathrm{f}_{\mathrm{C}}^{\mathrm{A}} \mathrm{g}$, section dimensions, foundation and

bearing flexibility, participating mass, height

of pier

1

\begin{tabular}{|c|}
\hline Guess $\rho_{t}^{*}$, choose $f_{y}$ and $f_{c}^{\prime}$ \\
\hline Calculate $\rho_{t}^{*} m=\rho_{t}^{*} f_{y} / 0.85 f_{c}^{\prime}$ \\
\hline
\end{tabular}

\section{1}

Determine flexural stiffness of energy dissi-

pating member, EI, using charts 5.1 to 5.5 and

calculate overall structural stiffness $k$,

and period of vibration, $T$.

Section 5

Determine damage ductility factor, $\mu_{d}$, using charts 6.1 to 6.21

Find lateral design load reduction factor $R_{d}$ from chart 6.22

\section{1}

From the appropriate design spectrum find the coefficient $C_{\text {f }}$ and $C$ (for the maximum design

ductility factor allowed by the governing

loading codel corresponding to the period of vibration, $\mathrm{T}$.

Calculate $H_{d}=\frac{C_{\mu=1}}{R_{d}} M g$

and $\mathrm{H}_{\mu}=\mathrm{C}_{\mu} \mathrm{ZMg}$

Analyse substructure for the greater of $\mathrm{H}_{\mathrm{d}}$ and

$\mathrm{H}_{H}$ using an appropriate analysis. Design

plastic hinging members for resulting reactions,

including factor $\mathrm{K}^{*}$ to allow for strength

increase due to colfinement

Result: $\rho_{t}$

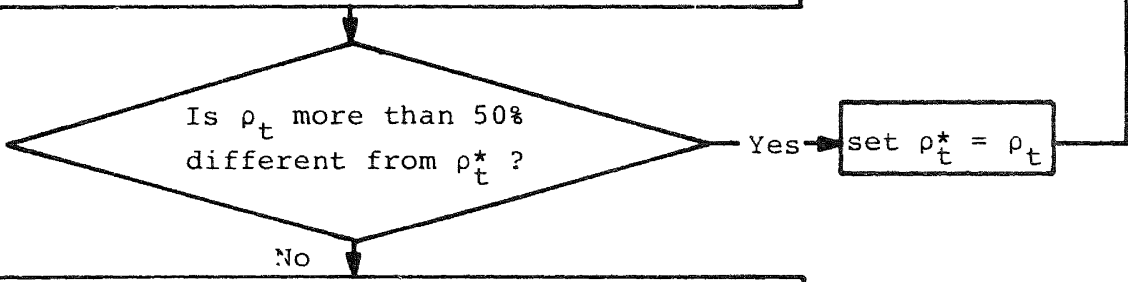

Choose number and diameter of reinforcing bars to provide $\rho_{t}$.

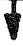

GO TO II

Fig. 6 Flow Chart for Design Aid for Flexural Strength and Ductility of Reinforced Concrete Bridge Piers. 


\section{DESIGN THE PLASTIC HINGES TO MATCH THE REQUIRED DUCTILITY}

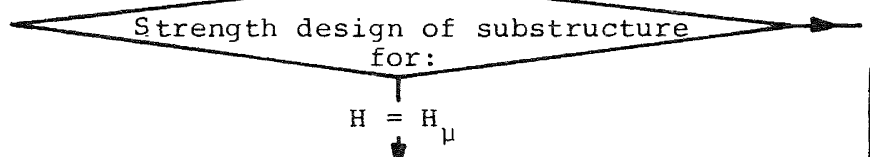

$\mathrm{H}=\mathrm{H}_{\mathrm{d}}$

Use chart 6.23 to

determine the ductility

factor $\mu$ that may

develop in the design

Available structure ductility must be at least

6

equal to allowable $\mu$ (from relevant loading code).

calculate the required curvature ductility

factor $\phi_{1} / \phi_{Y}$ for which to detail the plastic

hinge zone.

8

For $\phi_{\mu} / \phi_{y}$, the given axial load ratio $\mathrm{P}_{\mathrm{e}} / \mathrm{f}_{\mathrm{C}} \mathrm{A}$

and the mechanical reinforcing ratio $\rho$ m

(determined in 5) find a value $\mathrm{f}_{\mathrm{r}} / 0.85 \mathrm{f}$

using charts 9.1 to 9.31

Choose the arrangement of the transverse steel

Using charts 10.1 or 10.2 for circular sections and eqns. 10.2 to 10.4 plus charts 10.3 to 10.7 for rectangular or flanged sections, determine the diameter of the transverse bars, $d_{h}$, keeping the hoop spacing $s_{h} \leqq 6 d_{b}$ (or $\leqq 5 d_{b}$ if $h_{\text {so }}$ assumed in 8). Calculate $\mathrm{A}_{\mathrm{sh}}$.
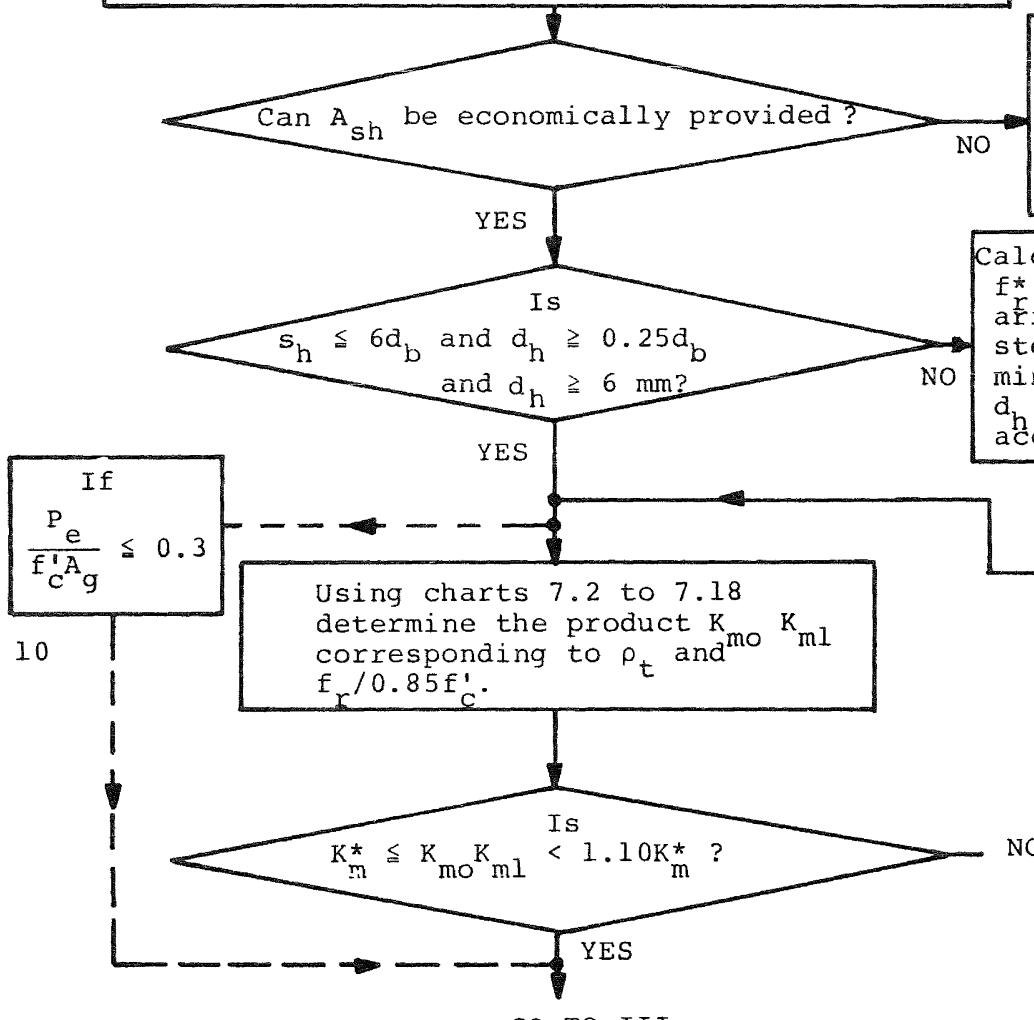

NO minimum requirement for $s_{h}$ '
$d_{h}$ and recalculate $A_{s h}$
accordingly.

Design for smaller ductility factor, i.e. go back to 4 with a smaller $\mu$, or increase pier size to reduce $\mathrm{P}_{\mathrm{e}} / \mathrm{f}^{\prime} \mathrm{A}$.

alculate the confining stres $\mathrm{f}^{*}$, corresponding to an teel satisfying the

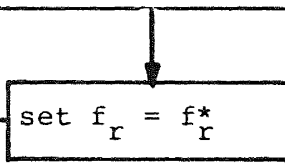

GO BACK TO 5 NO set $K_{m}^{*}=K_{m o} K_{m I}$ 


\section{DESIGN FOR SHEAR AND DESIGN THE PARTS OF THE STRUCTURE RESISTING THE PLASTIC OVER-STRENGTH MOMENT OF THE PLASTIC HINGES

\author{
FROM II
}

Calculate plastic over-strength moment, M corresponding to the provided confining stress using charts 7.2 to 7.20 and the material overstrengths

Refer to

Section $7 b$

Place the quantity $A$ with $s_{h} \leqq 6 d_{\text {for }} \leqq 5 d_{b}$ if so assumed) in the potential plastic hinge region and the quantity $A$ over the remainder of the column. Observe the requirements in section 10.2 for the transition zone.

Calculate the design shear force from $M$ and design the energy dissipation member for shear. The contribution $\mathrm{V}_{\mathrm{C}}$ inside the plastic hinge region as well as over the remainder of the column shall be calculated using the specified concrete cylinder strength, $f_{c}^{\prime}$

Result: area of transverse steel required for shear, A (in plastic hinge region) and Ave (over remainder of column)

$$
\text { section } 10.2 \text { for the transition zone. }
$$

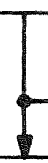

Design the parts of the structure resisting $M$. Their ideal flexural and shear strengths, caldulated using appropriate material strengths $f^{\prime}$ and $f$, shall be at least equal to the moments and forces arising due to the moment $M_{0}$ in the plastic hinges.

Because the material strengths used in 11 to calculate $M$ contain a 10 to $25 \%$ strength enhancement to allow for dynamic strain rate effects, and because the soil can also be expected to be at least $10 \%$ stronger under dynamic loads, a $10 \%$ reduction of the loads derived from $M_{0}$ is allowed for designing the foundations.

Place the quantity $A$ with $\mathrm{s}_{\mathrm{h}} \leqq 6 \mathrm{~d}_{\mathrm{p}}$ (or $\leqq 5 \mathrm{~d}_{\mathrm{b}}$ iłp $\mathrm{p}_{\text {so }}$ assumed in the potential plastic hinge region and the quantity $\bar{A}$ over the remainder of the column. Observe the requirements in section 10.2 for the transition zone.

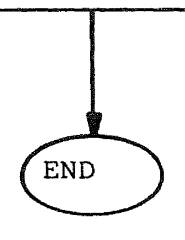

Fig. 6 (Continued) 
ductility factors in the plastic hinges that do not cause spalling of the cover concrete. The damage threshold curvature ductility factors are given in a set of charts included in the revised design aid publication CDP $810 / B$ [7].

For axial compressive loads less than $0.3 \mathrm{f}^{\prime A} \mathrm{~A}$ the ideal flexural strength is almost $t^{g}$ independent of the confining stress and hence there will generally be no need to loop back to step 5 in the flow chart after the confining stress has been determined in step 8 . This is indicated by the dashed line in step 10 shown in Fig. 6. Thus the design procedure will be less complex than it actually appears in the flow chart. However, it is evident that for large axial loads a few iteration cycles may be necessary before a solution is found. Note that the factors $\mathrm{K}_{\mathrm{mo}}$ and $K_{\text {m }}$ referred to in step 10 of the mo flow chart are the strength enhancement factor due to confinement, $M_{i} / M_{\text {code }}$, while $\mathrm{K}_{\mathrm{m}}^{*}$ is a first estimate of that codactor.

\section{IMPLICATION OF RESULTS AND COMPARISON WITH NZS 3101 EQUATIONS}

The ductility design charts prepared in dimensionless form (for example, Fig. 4) allow the designer to determine the required confining stress, $f_{r}$, for a given reinforced concrete column section, axial load and curvature ductility demand to be met. From the calculated confining stress necessary for a particular situation it is then possible to determine the quantity of transverse spiral or hoop steel necessary to provide that confining stress. The quantity of transverse steel is expressed by the volumetric steel percentage $\rho_{s}$ for columns confined by circular hoops or spirals and by the combined transverse steel area $A_{\text {sh }}$ within the hoop spacing $s_{h}$ for rectangular sections.

In order to compare the quantity of confining steel required by Eqs. I to 4 (that is, the equations from the concrete design code [1]) with the results of the detailed procedure outlined in this paper, the quantities $\rho_{s}$ for a typical circular section and $\mathrm{A}$ for a typical rectangular section were shound using the appropriate ductility design charts. The confining stresses given by the charts for the circular section to achieve a curvature ductility factor of 16 at a range of different axial compression load levels were converted into volumetric ratios $\rho$ and plotted against the axial load leves $P / F^{\prime} A$ in Fig. 7. A curvature ductility facEor of 16 was considered to be the minimum available when satisfyina the concrete design code [1] requirements for adequate ductility. Note that the strength reduction factor in NZS $3101 \mathrm{Er} .2$ has been taken as unity. Also included in Fig. 7 is the quantity of confining steel required by the SEAOC [8] and ATC [9] codes, which is independent of the axial load level. Although the comparison in Fig. 7 only applies to a particular circular column example (the column properties are given in Fig. 7), it can be concluded that the $\rho_{s}$ values determined using the design charts depend more significantly on the axial load ratio than indicated by the concrete design code [1] equations. While the code design equations are quite conservative for axial load levels less than 0.35 , they may be unconservative for higher axial load levels, particularly when the quantity of flexural steel in the column is small. For columns on flexible foundations, where the curvature ductility factor demand for a given displacement ductility factor is likely to be much greater than 16, the concrete design code equations may be unconservative even for axial load levels $P / f^{\prime A}<0.35$. A further observation is that the quantity of confining steel required depends on the flexural steel content, a factor which is not taken into account by the concrete design code equations.

Fig. 8 shows a similar comparison for the quantity $A$ required for a rectangular column with the properties given in that figure. In this case only one flexural steel content was considered $\left(\rho_{t} \mathrm{~m}=0.2\right)$ and the $A$ values were determined from the corresponding charts for four different curvature ductility factors. The figure also includes the $A$ required by the SEAOC [8] and ATC [9] codes, as well as by Eqn. 4 of the concrete design code [1], and by a modified form of Eqn. 4 suggested by Park [10]. The strong dependence of $A$ on the axial load ratio is also evident in Fig. 7. While for $\mathrm{P} / \mathrm{F}^{\prime A}<0.35$ all three code and modified codegrelationships are conservative for $\phi / \phi$ of up to 23 , they become less conservative or unconservative for axial load levels greater than 0.35 . For flexural steel contents less than $\rho_{t} m=0.2$ the concrete design code [1] equations would be less conservative than shown in Fig. 8, while for $\rho_{t} m>0.2$ they would be more conservative.

\section{POSSIBLE FUTURE DEVELOPMENTS}

By determining the quantities of confining steel required for a range of different curvature ductility factors, axial load levels, flexural steel contents, relative concrete cover thicknesses, and for either Grade 275 or Grade 380 transverse steel, using the corresponding ductility design charts, the influence of each of these variables on $\rho$ or $A$ can be evaluated. In this way it wouldh be possible to derive more accurate design equations, suitable for the concrete design code, for circular and rectangular columns taking into account all the important parameters.

Such a design equation could be made up of a number of factors, each factor depending in some form on one of the variables identified above. The required curvature ductility factor could be a variable in these design equations, resulting in a better match of available and required curvature ductility than can be achieved with the present concrete design code equations. Although the resulting equation would be considerabiy more complex the advantage of more rational and less conservative design would appear to outweigh this. In any case 


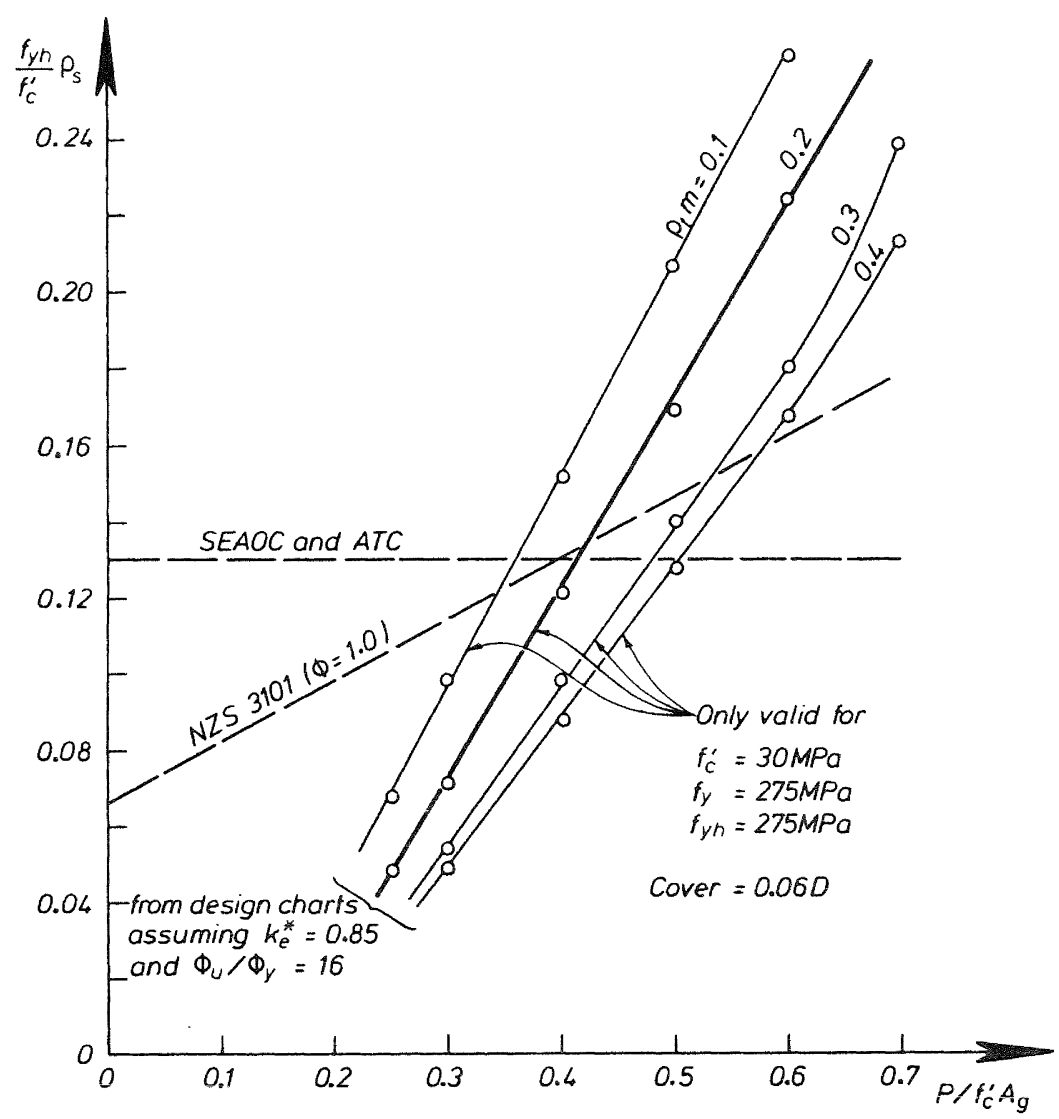

Fig. 7 Required Amount of Confining Steel for Ductility in Plastic Hinge Region of Circular Columns and Comparison With Requirements of NZS 3101, SEAOC and ATC [5].

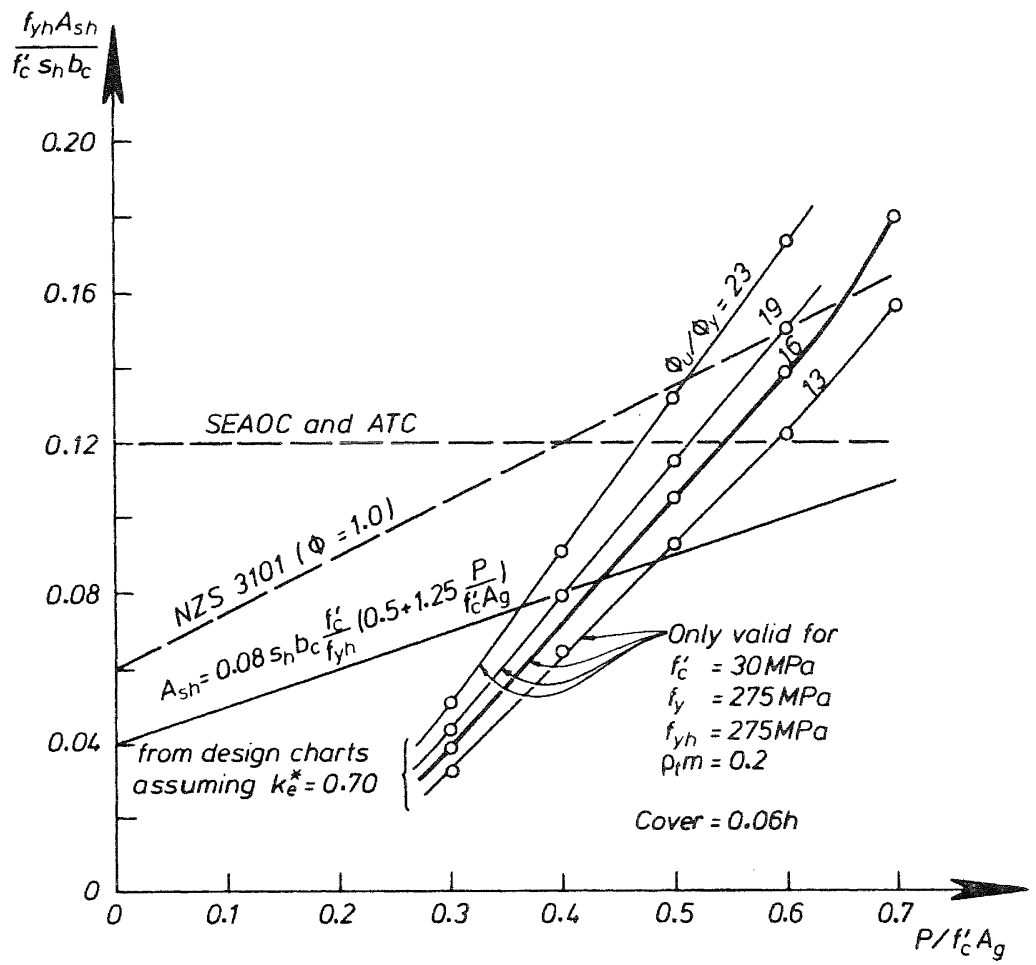

Fig. 8 Required Amount of Confining Steel for Ductility in Plastic Hinge Region of Rectangular Columns and Comparison with Requirements of NZS 3101, SEAOC and ATC [5]. 
charts could be drawn up to enable easier use of the equation. A further advantage would be that there would need to be only one equation for each section type (circular and rectangular) and that possibly the two equations could even be combined in one design equation.

\section{CONCLUSIONS}

New design charts have been derived to relate the available curvature ductility factor of reinforced concrete column sections to the magnitude of the confining stress applied by transverse hoop steel and to determine the flexural strength of those confined sections. The design charts were derived from theoretical studies of the cyclic moment-curvature behaviour of reinforced concrete column sections, using a computer analysis program that includes the cyclic stressstrain relationships for concrete and longitudinal reinforcing steel and takes into account the accumulation of strain energy in the transverse confining steel. The results were compared with the confining steel requirements of the New Zealand concrete design code NZS 3101 [1]. The most important results of the analyses and the comparison were:

(a) The quantity of confining steel required to meet a curvature ductility factor demand in the order of 15 to 20 is less than that calculated using the concrete design code equations for axial load levels $P / f^{\prime A}<0.35$, but may be greater for $\mathrm{P} / \mathrm{f}_{\mathrm{C}}^{\mathrm{G}} \mathrm{g}>0.35$.

(b) The quantity of confining steel required to meet any particular curvature ductility demand increases with decreasing flexural steel content and with increasing relative cover thickness.

(c) Provided that $\rho_{t} m<0.3$ the influence of the yield strength of the longitudinal steel on the quantity of confining steel may be neglected. That is, Grade 380 flexural steel may be used in the plastic hinge zone.

(d) Provided that $25 \mathrm{MPa} \leq \mathrm{f}^{\prime} \leq 35 \mathrm{MPa}$ the quantity of confining stee 1 increases proportionally to $f^{\prime}$ for a given axial load level and curvăture ductility factor.

(e) For $\rho \mathrm{m}<0.2$ and curvature ductility factor demands no greater than 15 to 20 , the quantity of confining steel may be decreased by a factor equal to $275 / 380$ if Grade 380 steel is used for transverse reinforcement for confinement rather than Grade 275 steel. For higher curvature ductility factor demands, or for $\rho_{t} \mathrm{~m}>0.2$ this proportional reduction is not always safe since it may result in hoop fracture before the required curvature ductility factor is reached.

(f) There is a substantial increase in the flexural strength of columns due to confinement of the concrete for axial compression loads greater than $0.3 f_{C}^{\prime} A{ }^{\prime}$ For smaller compression loads this increase is negligible for typical amounts of confining steel. (g) The maximum moment reached during response to a severe earthquake is further increased by strain hardening of the longitudinal steel. This moment, determined for overstrength material properties, should be used for the overstrength moment in capacity design.

(h) The design charts for reinforced concrete bridge columns are part of a comprehensive seismic design procedure, illustrated by a flow chart. This procedure may require some iterative steps (trial and error) in order to determine the quantity of longitudinal and hoop steel. However, for the design of columns with $\mathrm{P} / \mathrm{f}^{\prime} \mathrm{A}<0.3$ the first trial often results in ${ }^{\mathrm{a}}{ }^{\mathrm{g}}$ satisfactory solution.

\section{ACKNOWLEDGEMENTS}

This study was conducted by Dr. F.A. 2ahn during his PhD research at the University of Canterbury under the supervision of Professor R. Park and Dr. M.J.N. Priestley, and continued by Dr. Zahn and Mr. H.E. Chapman ir the Civil Directorate of the Head Office of the Ministry of Works and Development, Wellington. Thanks are due to the Road Research Unit of the National Roads Board, the University of Canterbury and the Ministry of Works and Development for financial support during the project.

\section{REFERENCES}

[1] "Code of Practice for the Design of Concrete Structures (NZS 3101 Part 1 . 1982)" , Standards Association of New Zealand, Wellington, 1982, 127pp.

[2] "Ductility of Bridges with Reinforced Concrete Piers", Civil Division Publication CDP $810 / \mathrm{A}$, Ministry of Works and Development, Wellington, April 1975, I09pp.

[3] Priestley, M.J.N. and Park, R. "Strength and Ductility of Bridge Substructures", Bulletin 71, Road Research Unit, National Roads Board, Wellington, 1984, 120pp.

[4] Mander, J.B., Priestley, M.J.N. and Park, R., "Seismic Design of Bridge Piers", Research Report 84-2, Department of Civil Engineering. University of Canterbury, February $1984,483 \mathrm{pp}$.

[5] Zahn, F.A., Park, R. and Priestley, M.J.N., "Design of Reinforced Concrete Bridge Columns for Strength and Ductility", Research Report 86-7, Department of Civil Engineering, University of Canterbury, March'1986, $330 \mathrm{pp}$.

[6] "Code of Practice for General Structural Design and Design Loadings for Buildings (NZS 4203:1984)" Standards Association of New Zealand, Wellington, 1984, 100pp.

[7] Revision of CDP 810/A "Ductility of Bridges with Reinforced Concrete Piers", Ministry of Works and Development (in preparation). 
[8] "Recommended Lateral Force Requirements and Commentary", Structural Engineers Association of California, San Francisco, 1980.

[9] Applied Technology Council, "Seismic Design Guidelines for Highway Bridges", ATC-6, Applied Technology Council, Berkeley, California, October 1981 200pp.

[10] Park, R., "Section 6: Flexure With and Without Axial Load", Applications of New Zealand Standard Code of Practice for the Design of Concrete Structures NZS 3101 : 1982, New Zealand Concrete Society Technical Report No.2, August 1983 .

\section{NOTATION}

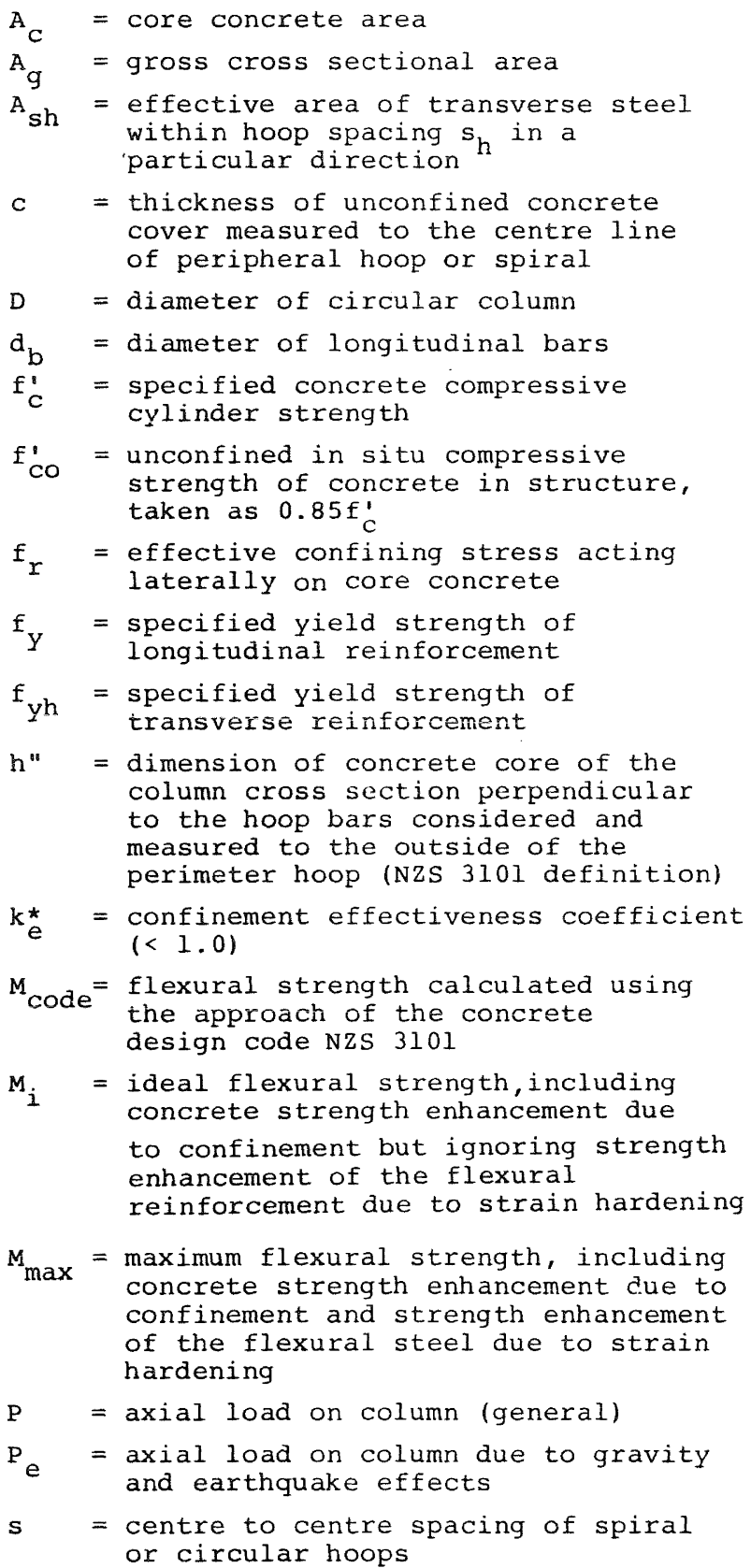

$M_{i} \quad=$ ideal flexural strength, including concrete strength enhancement due to confinement but ignoring strength enhancement of the flexural reinforcement due to strain hardening

$M_{\max }=$ maximum flexural strength, including concrete strength enhancement due to confinement and strength enhancement of the flexural steel due to strain hardening

$\mathrm{P} \quad=$ axial load on column (general)

$\mathrm{P}_{\mathrm{e}}=$ axial load on column due to gravity and earthquake effects

$\mathbf{s}=$ centre to centre spacing of spiral or circular hoops

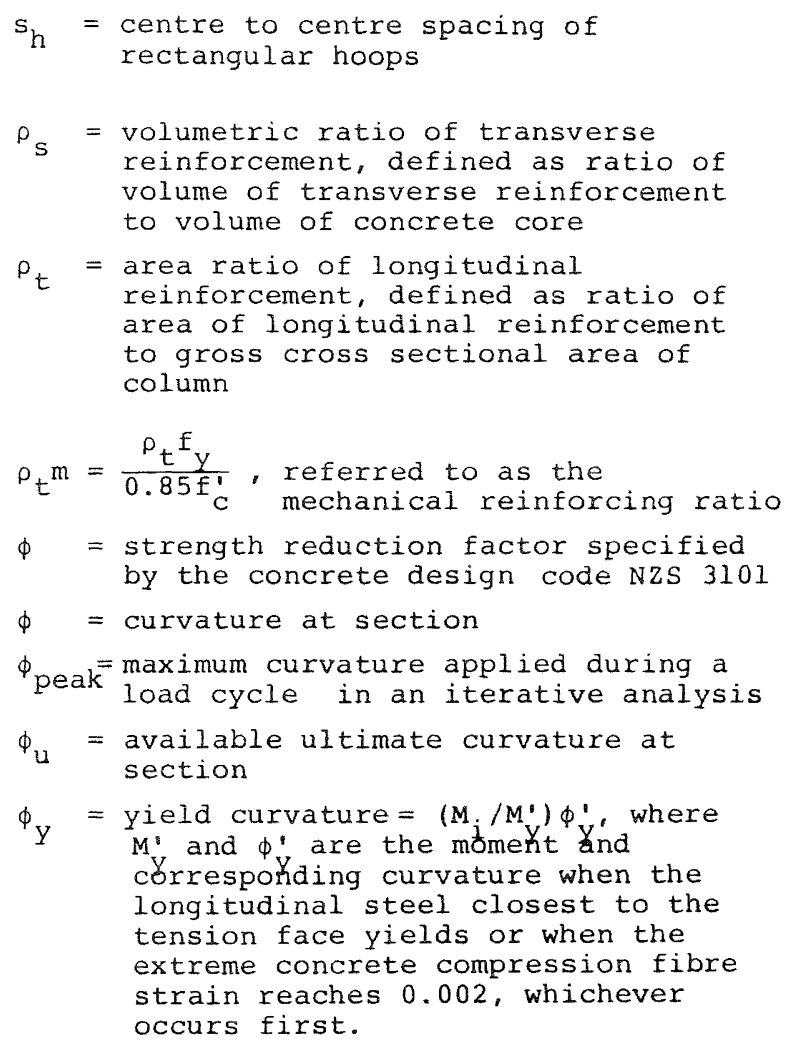

